\title{
Seasonal variations of allergenic pollen in a Mediterranean region - Alexandroupolis, north-east Greece
}

\author{
Christos Nikolaidis ${ }^{1 \dagger}$, Michael Katotomichelakis ${ }^{2 \dagger}$, Evangelia Nena', Michael Makris ${ }^{3}$, \\ Marios Tsakas', Ioannis Michopoulos' ${ }^{1}$, Theodore C. Constantinidis' ${ }^{1}$, Vassilios Danielides ${ }^{2}$ \\ ${ }^{1}$ Laboratory of Hygiene and Environmental Protection, Medical School, Democritus University of Thrace, Alexandroupolis, \\ Greece \\ ${ }^{2}$ Department of Otorhinolaryngology, Medical School, Democritus University of Thrace, Alexandroupolis, Greece \\ ${ }^{3}$ Allergy Unit "D. Kalogeromitros", 2nd Department of Dermatology and Venereology, Medical School, University of Athens, \\ "Attikon" University Hospital, Athens, Greece
}

${ }^{\dagger}$ Both authors contributed equally to this work.

Nikolaidis C, Katotomichelakis M, Nena E, Makris M, Tsakas M, Michopoulos I, Constantinidis TC, Danielides V. Seasonal variations of allergenic pollen in a Mediterranean region (Alexandroupolis, north-east Greece). Ann Agric Environ Med. 2015; 22(4):685-689. doi: 10.5604/12321966.1185776

\begin{abstract}
Objectives. The aim of this study was to describe the aerobiological characteristics of NE Greece, identify the most prevalent taxa, define the duration of the main pollen season and correlate allergen records with meteorological parameters. Materials and method. A 7-day volumetric trap, running continuously throughout the year, was used to collect circulating pollen. Pollen taxa were characterized by standard protocols and counted as grains $/ \mathrm{m}^{3}$. The main pollen season was deduced from these data and running means (10-day averages) were plotted against time. Correlations with climatic factors (temperature, rain, humidity, wind velocity) were assessed by single linear regression analysis.

Results. In total, 11 pollen families were identified, including 6 arboreal and 5 non-arboreal taxa. The 5 most prevalent taxa were Oleaceae, Fagaceae, Poaceae, Cupressaceae and Pinaceae. Peak pollen concentrations were detected in April and May, with daily averages exceeding 410 grains $/ \mathrm{m}^{3}$. Compositeae had the longest pollen season of 135 days and Oleaceae the shortest, extending to only 27 days. Correlations with meteorological parameters showed variable associations among different taxa, with mean temperature $(p<0.001)$, relative humidity $(p=0.015)$, and wind speed $(p=0.042)$ emerging as the most significant determinants as regards total pollen counts.

Conclusions. Describing the aerobiological characteristics of NE Greece enabled the identification of allergenic risks that are specific for this region. Records generated in this study can be used to alert sensitized individuals of prevailing seasonal patterns, in order to take necessary precautions against imminent exposures. The monitoring system established here can serve as a reference guide for future epidemiological research focusing on allergic asthma and rhinitis.
\end{abstract}

\section{Key words}

Allergenic pollen, seasonal trends, Mediterranean, NE Greece

\section{INTRODUCTION}

The monitoring of aerobiological parameters is of paramount importance for the characterization of allergenic risks. Pollen allergy (hay fever/pollinosis) is caused by a hypersensitivity reaction of the respiratory tract and eye conjunctivae to pollen grains. It includes allergic rhinitis, allergic conjunctivitis, allergic bronchial asthma, and less frequently, urticaria [1]. Seasonal allergies are often characterized by the recurrence of symptoms which show periods of improvement and relapse [2]. The allergic manifestations are more prevalent during the plant pollination season; hence, accurate descriptions of its start and end periods are important for both patients and clinicians alike $[3,4,5]$.

Particularities at the epidemiological level are directly linked to environmental factors which, in turn, are determined by the geographic zone and local vegetation

Address for correspondence: Christos Nikolaidis, Laboratory of Hygiene and Environmental Protection, Medical School, Democritus University of Thrace, Alexandroupolis, Evros, Greece

E-mail: cnikolae@med.duth.gr

Received: 09 October 2014; accepted: 19 January 2015 patterns. The phenological stage of plant species and climatic conditions are crucial for elucidating seasonal patterns and assigning patient records with respect to these variables. Information of this type can be used to establish early warning systems and alert public health authorities, advance our medical understanding of disease manifestations in a region, and promote population-based screening options that can ultimately lead to better treatment regimes [6].

Airborne particles can be dispersed in the atmosphere and travel great distances, although local sources are typically more potent in inducing allergenic reactions. Climatic factors, such as air temperature, humidity, rainfall and wind speed/direction are key modifiers of pollen dissemination, as well as of respiratory tract sensitization. They may cause rapture of pollen grains, releasing thousands of allergenic particles into the air and elicit acute reactions in sensitized individuals $[7,8]$.

The Mediterranean environment in particular is dominated by aeroallergens that correspond to a plethora of flora, including both arboreal and herbaceous taxa that flourish in the temperate climate throughout the calendar year [9]. This poses a challenge for individuals suffering from asthma 
and rhinitis, as well as for medical institutions dealing with these types of morbidities.

\section{OBJECTIVES}

The aim of this study was to analyze pollen dynamics in NE Greece, describe their seasonal trends and correlate them with meteorological parameters. These preliminary data can help establish a pollen monitoring system that alerts susceptible individuals, and can provide critical evidence for future epidemiological studies focusing on allergic respiratory diseases in the region.

\section{MATERIALS AND METHOD}

The city of Alexandroupolis is situated in North-Eastern (NE) Greece, at 40.51' N 25.52' E. It has a typical Mediterranean climate, with an average daily temperature of $14.9^{\circ} \mathrm{C}$, relative humidity of $67.4 \%$ and $549.3 \mathrm{~mm}$ total precipitation per year. It is situated near the delta of the Evros river, $40 \mathrm{~km}$ from the border with Turkey, $302 \mathrm{~km}$ West of Instanbul and $750 \mathrm{~km}$ North-East of Athens (Fig. 1). Local vegetation includes evergreen, deciduous and fruit trees (e.g. pines, cypresses, oaks and olives), as well as a variety of other shrubs, grasses and herbs (e.g. mugwort, laurel, mint, thyme) that create a diverse polinological environment.

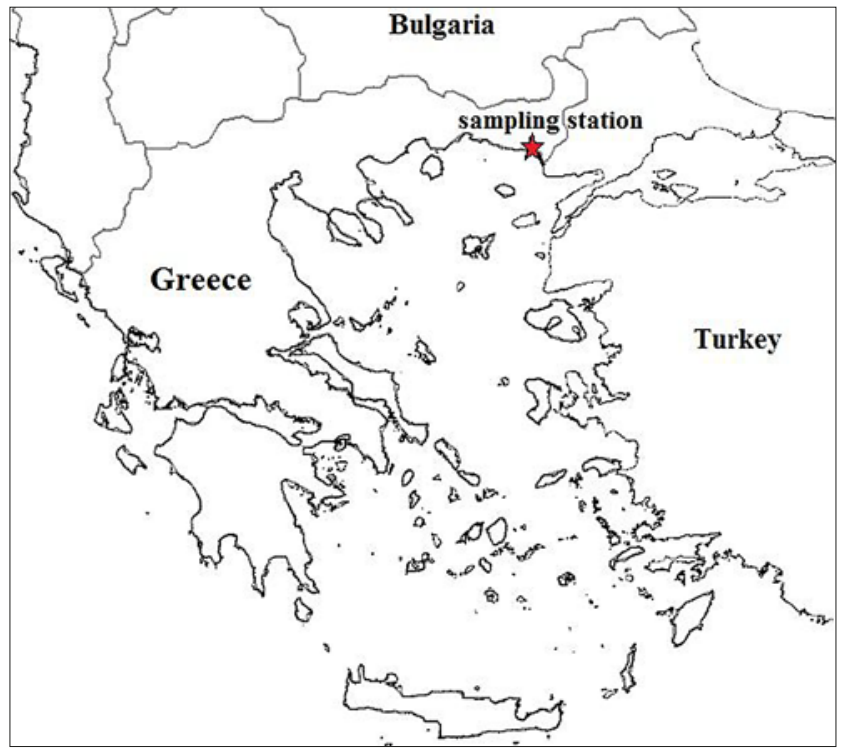

Figure 1. Map of study region

For pollen capturing, a 7-day recording volumetric spore sampler (Burkard Scientific, Ltd.) was placed $21 \mathrm{~m}$ above the ground, on the roof of the University Hospital of Evros, which is $6 \mathrm{~km}$ West of the city of Alexandroupolis. The unit was operating continuously for one year (January-December 2013), collecting 10 liters of air per minute. A strip of siliconecoated Melinex tape was exposed to the air for trapping the spores, and was changed once a week. The exposed tape was cut into $48 \mathrm{~mm}$ segments representing $24 \mathrm{~h}$ periods. These segments were mounted on microscopic slides using Gelvatol mixed with a stain (acid fuchsin) to enable visualization under a high resolution light microscope (Olympus BX40) at $400 \times$ magnification.

Pollens were identified following standard manuals [10] and counted according to the guidelines of the British Aerobiology Federation [11]. The spore counts were converted into the number of spores per cubic meter of air. Seasonal distribution of pollen counts was presented as 10-day-running average. The main pollen season (MPS) was characterized as $90 \%$ of the seasonal pollen count, starting on the day when $5 \%$ of the total pollen had been recorded, and ending on the day $95 \%$ of the total pollen had been counted.

Meteorological data were obtained from the regional station of the Hellenic National Meteorological Service situated close to the sampling site (http://www.hnms. gr). Daily mean temperature $\left({ }^{\circ} \mathrm{C}\right)$, relative humidity (\%), rainfall $(\mathrm{mm})$, wind speed $(\mathrm{km} / \mathrm{h})$ and wind direction were recorded. The correlation between individual meteorological parameters and pollen counts was assessed by regression analysis, using SPSS $15.0^{\circledR}$ software package (http://www. spss.com). A value of $\mathrm{p}<0.05$ was considered to be statistically significant.

\section{RESULTS}

Airborne pollen belonging to 11 families were identified in the study, including 6 arboreal (Cupressaceae, Pinaceae, Fagaceae, Platanaceae, Betulaceae and Oleaceae), and 5 non-arboreal taxa (Poaceae, Plantaginaceae, Compositeae, Chenopodiaceae and Urticaceae). Running means (or moving averages) for 10 days were used for smoothing the values, in order to make the trend of seasonal variation more easily observed (Fig. 2). Pollen taxa were widely distributed throughout the calendar year, and peaked during the spring and summer months (March-September).

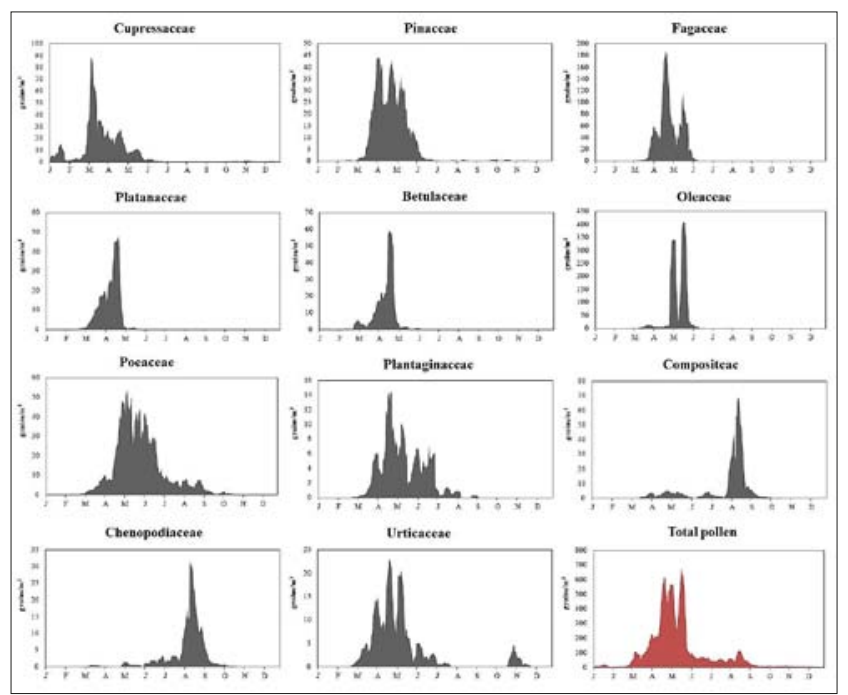

Figure 2. Pollen concentrations (grains $/ \mathrm{m}^{3}$ ) as 10 -day running averages

The major pollen producers were arboreal plants, namely Oleaceae (24.1\%), Fagaceae (13.7\%), Cupressaceae (7.6\%) and Pinaceae (5.9\%), which accounted for $51.3 \%$ of the total pollen grains (Fig. 3). The family Oleaceae was dominated by Olea europaea (olives), followed by Fraxinus and Ligustrum species. Fagaceae were principally represented by Quercus 


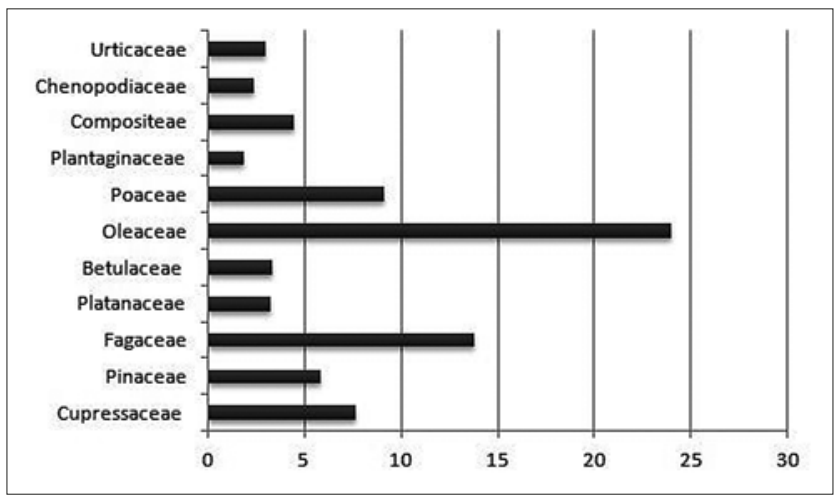

Figure 3. Annual contribution (\%) of individual pollen on total atmospheric load

spp. (oaks), Cupressaceae were associated with Cupressus or Juniperus spp. and Pinaceae included a mixture of Pinus, Abies or Cedrus taxa.

Among non-arboreal plants, pollen grains belonging to Poaceae (9.1\%), Compositeae (4.4\%) and Urticaceae (3\%) dominated the atmosphere during the study period. Poaceae generated a diverse sample, including both domesticated and wild flowering (monocotyledonous) plants. Compositeae (also known as Asteraceae) included a large variety of taxa with a characteristic morphology (e.g. Ambrosia or Artemisia spp.). Finally, Urticaceae (Parietaria spp.) were the smallest pollen grain recorded, measuring only $12-15 \mu \mathrm{m}$ in diameter.

The main pollen season (MPS) was described as the time during which most pollen (90\%) was recorded, starting when the sum of daily means concentrations reached $5 \%$ of the total sum, up to the point when the sum reached 95\% [12]. The pollination of all arboreal species initiated and peaked during springtime, with the exception of Cupressaceae that started their circulation in January (Tab. 1). The pollen season of Pinaceae, Platanaceae, Betulaceae and Urticaceae started in March, of Fagaceae, Poaceae, Plantaginaceae and Compositeae in April, whereas Oleaceae and Chenopodiaceae seasons initiated in May and June, respectively.

Termination of the pollen season for all arboreal taxa was observed in spring (or early summer in the case of Pinaceae). On the other hand, herbaceous taxa pollination extended to late summer (Poeaceae) and early autumn (Compositeae, Chenopodiaceae). Peak dates for all pollen types occured in spring (April-May), with the exception of Compositeae and Chenopodiaceae, which peaked in August. Moreover,
Compositeae had the longest pollen season (135 days), followed by Utricaceae and Poeaceae (134 days). Among arboreal taxa, Cupressaceae had the longest pollen season of 122 calendar days.

April and May were the months when the highest concentrations of airborne pollen (8 taxa) was observed. During these months, an average of 410 pollen grains per $\mathrm{m}^{3}$ circulated in the atmosphere. The highest concentrations of pollen counts (over 1,000 grains per $\mathrm{m}^{3}$ ) were recorded in May and the lowest $\left(<1\right.$ grain per $\left.\mathrm{m}^{3}\right)$ in December. Notably, Oleaceae had the shortest pollen season of just 27 days, although they presented the maximum of pollen load in the atmosphere $\left(7,742\right.$ grain per $\left.\mathrm{m}^{3}\right)$ during their seasonal circle.

In the present study, 4 climatic factors, namely average daily temperature $\left({ }^{\circ} \mathrm{C}\right)$, relative humidity $(\%)$, rainfall $(\mathrm{mm})$ and wind speed $(\mathrm{km} / \mathrm{h})$, were taken into consideration (Tab. 2). Based on these records, August was the warmest $\left(26.6 \pm 1.3^{\circ} \mathrm{C}\right)$ and driest month of the year $(0 \mathrm{~mm}$ rain, $47.7 \pm 6.3 \%$ humidity). January, on the other hand, was the wettest month $(3.8 \pm 8.3 \mathrm{~mm}$ rain, $80.8 \pm 7.8 \%$ humidity) and December the coldest $\left(4.9 \pm 2.8^{\circ} \mathrm{C}\right)$. August was also the windiest month $(9.6 \pm 5.6 \mathrm{~km} / \mathrm{h})$ and September the calmest $(4.0 \pm 1.6 \mathrm{~km} / \mathrm{h})$. North-easterly winds dominated throughout the year which tended to disperse airborne pollen in southwestern directions, away from the mainland and over the Aegean sea.

Table 2. Climatic conditions (mean \pm SD)

\begin{tabular}{lccccc}
\hline Month & $\begin{array}{c}\text { Temperature } \\
\left({ }^{\circ} \mathrm{C}\right)\end{array}$ & $\begin{array}{c}\text { Rainfall } \\
(\mathrm{mm})\end{array}$ & $\begin{array}{c}\text { Relative } \\
\text { humidity }(\%)\end{array}$ & $\begin{array}{c}\text { Wind speed } \\
(\mathrm{km} / \mathrm{h})\end{array}$ & $\begin{array}{c}\text { Wind } \\
\text { direction }\end{array}$ \\
\hline January & $7.7 \pm 3.5$ & $3.8 \pm 8.3$ & $80.8 \pm 7.8$ & $5.9 \pm 5.6$ & $\mathrm{NE}$ \\
\hline February & $7.5 \pm 3.0$ & $3.7 \pm 5.9$ & $79.3 \pm 6.8$ & $8.6 \pm 6.0$ & $\mathrm{NE}$ \\
\hline March & $10.1 \pm 3.3$ & $2.5 \pm 6.8$ & $75.9 \pm 7.6$ & $7.4 \pm 4.0$ & $\mathrm{ENE}$ \\
\hline April & $13.9 \pm 3.1$ & $0.8 \pm 2.3$ & $68.7 \pm 10.4$ & $7.0 \pm 5.4$ & $\mathrm{NE}$ \\
\hline May & $20.0 \pm 2.0$ & $0.1 \pm 0.5$ & $64.6 \pm 8.2$ & $7.8 \pm 5.4$ & $\mathrm{SW}$ \\
\hline June & $22.1 \pm 3.1$ & $2.5 \pm 7.0$ & $62.6 \pm 11.4$ & $6.1 \pm 3.0$ & $\mathrm{NE}$ \\
\hline July & $25.3 \pm 1.7$ & $0.8 \pm 0.5$ & $49.3 \pm 4.9$ & $8.4 \pm 6.0$ & $\mathrm{NE}$ \\
\hline August & $26.6 \pm 1.3$ & 0 & $47.7 \pm 6.3$ & $9.6 \pm 5.6$ & $\mathrm{NE}$ \\
\hline September & $20.6 \pm 1.7$ & $1.2 \pm 3.6$ & $61.9 \pm 11.4$ & $4.0 \pm 1.6$ & $\mathrm{NNW}$ \\
\hline October & $13.7 \pm 2.9$ & $2.2 \pm 6.7$ & $71.5 \pm 11.7$ & $4.7 \pm 3.6$ & $\mathrm{NE}$ \\
\hline November & $12.2 \pm 3.5$ & $4.4 \pm 9.3$ & $79.7 \pm 9.0$ & $5.9 \pm 5.6$ & $\mathrm{NE}$ \\
\hline December & $4.9 \pm 2.8$ & $0.2 \pm 0.4$ & $71.5 \pm 13.3$ & $7.1 \pm 6.5$ & $\mathrm{NE}$ \\
\hline & & & & &
\end{tabular}

Table 1. Characteristics of the pollen season

\begin{tabular}{|c|c|c|c|c|c|c|}
\hline Pollen type & Start date (5\%) & End date (95\%) & Season duration (days) & Peak date & Peak concentration ${ }^{1}$ & Total pollen' \\
\hline Cupressaceae & 23 January & 24 May & 122 & 15 March & 310.5 & 2468.7 \\
\hline Pinaceae & 29 March & 5 June & 79 & 11 April & 133.9 & 1983.4 \\
\hline Fagaceae & 5 April & 27 May & 53 & 27 May & 432.0 & 4499.3 \\
\hline Platanaceae & 19 March & 30 April & 43 & 26 April & 119.3 & 1049.9 \\
\hline Betulaceae & 9 March & 4 May & 57 & 26 April & 204.1 & 1072.2 \\
\hline Poaceae & 8 April & 19 August & 134 & 15 May & 184.1 & 2923.9 \\
\hline Plantaginaceae & 3 April & 6 July & 95 & 25 April & 61.0 & 608.12 \\
\hline Compositeae & 25 April & 6 September & 135 & 24 August & 108.5 & 1433.2 \\
\hline Chenopodiaceae & 13 June & 9 September & 89 & 22 August & 52.4 & 752.2 \\
\hline Urticaceae & 20 March & 31 July & 134 & 15 May & 76.1 & 953.6 \\
\hline
\end{tabular}


Table 3. Impact of climatic factors on atmospheric concentration of pollen (results from single linear regression analysis; only significant associations are shown)

\begin{tabular}{llcc}
\hline Pollen type & \multicolumn{1}{c}{ Climatic factor } & $\mathrm{B}(95 \% \mathrm{Cl})$ & $\mathrm{p}$ value \\
\hline Cupressaceae & Relative Humidity & $0.22(0.06,0.38)$ & $0.009^{* *}$ \\
\hline Oleaceae & Wind speed & $3.55(1.14,5.95)$ & $0.004^{* *}$ \\
\hline Poaceae & Mean Temperature & $0.77(0.52,1.01)$ & $<0.001^{* * *}$ \\
\cline { 2 - 4 } Plantaginaceae & Relative Humidity & $-0.24(-0.38,-0.11)$ & $0.001^{* *}$ \\
\hline Compositeae & Mean Temperature & $0.10(0.03,0.17)$ & $0.006^{* *}$ \\
\hline \multirow{2}{*}{ Chenopodiaceae } & Mean Temperature & $0.71(0.53,0.89)$ & $<0.001^{* * *}$ \\
\cline { 2 - 4 } & Relative Humidity & $-0.38(-0.47,-0.28)$ & $<0.001^{* * *}$ \\
\hline & Relative Humidity & $-0.21(-0.25,-0.16)$ & $<0.001^{* * *}$ \\
\cline { 2 - 4 } Total pollen & Wind speed & $0.17(0.04,0.30)$ & $0.012^{*}$ \\
\hline & Mean Temperature & $5.14(2.54,7.75)$ & $<0.001^{* * *}$ \\
\hline & Relative Humidity & $-1.76(-3.17,-0.35)$ & $0.015^{*}$ \\
\cline { 2 - 4 } & Wind speed & $3.97(0.15,7.79)$ & $0.042^{*}$ \\
\hline
\end{tabular}

B: coefficient of linear regression, Cl: confidence intervals, ${ }^{*} \mathrm{p}<0.05,{ }^{* *} \mathrm{p}<0.01,{ }^{* * *} \mathrm{p}<0.001$

The association between individual meteorological parameters and airborne pollen concentration was assessed by single linear regression analysis. The results of significant associations $(\mathrm{p}<0.05)$ are given in Table 3. Among arboreal taxa, Cupressaceae were associated with relative humidity $(\mathrm{p}=0.009)$ and Oleaceae with wind speed $(\mathrm{p}=0.004)$. Among non-arboreal taxa, Poaceae were associated with mean temperature $(p<0.001)$ and relative humidity $(p=0.001)$ and Plantaginaceae with mean temperature $(\mathrm{p}=0.006)$. Compositeae, on the other hand, were associated with mean temperature $(\mathrm{p}<0.001)$, relative humidity $(\mathrm{p}<0.001)$ and wind speed $(p=0.003)$. Equally, Chenopodiaceae correlated with mean temperature $(\mathrm{p}<0.001)$, relative humidity $(\mathrm{p}<0.001)$ and wind speed $(\mathrm{p}=0.012)$. Finally, total pollen were associated with mean temperature $(p<0.001)$, relative humidity $(p=0.015)$ and wind speed $(\mathrm{p}=0.042)$.

\section{DISCUSSION}

Allergic respiratory diseases, such as asthma and rhinitis, affect up to $40 \%$ of the global population [13]. Atmospheric pollen is the single most important inducer of allergies in susceptible individuals; thus, tight monitoring of phenological parameters is necessary to predict public risks. Plant pollination occurs on a seasonal basis, according to ecological and climatic factors that are specific for a region $[14,15]$.

Local vegetation patterns and geographic variables regulate phenological characteristics and dictate pollen dynamics. Aerobiological databases are therefore particularly useful in characterizing the start, peak and end of pollen season, and in alerting patients and physicians to take necessary precautions (e.g. avoid exposures, prescribe medications, etc.).

As the presented study shows, Oleaceae was the dominant taxon reaching a peak of 1,210 grains $/ \mathrm{m}^{3}$ in the beginning of May. This is no surprise as the area surrounding the sampling station is planted with olive trees to a radius of at least $15 \mathrm{~km}$. Olea europaea pollen is highly allergenic, albeit its pollination period was rather short, averaging only 27 calendar days. Other arboreal taxa, including Fagaceae (mainly Quercus spp.), Cupressaceae and Pinaceae that are less allergenic, extended their pollination time for longer periods.

Fagaceae were present in the atmosphere for 53 days, and peaked at the end of May with an average of 432 grains $/ \mathrm{m}^{3}$. Pinaceae circulated for 79 days, with a peak of 134 grains $/ \mathrm{m}^{3}$ recorded in mid-April, whereas Cupressaceae reached a maximum of 310 grains $/ \mathrm{m}^{3}$ in the middle of March, and were present in the atmosphere for a total of 122 days (January - May). Poaceae dominated the herbaceous taxa, reaching a maximum of 184 grains $/ \mathrm{m}^{3}$ in mid-May. Along with Compositeae, that peaked at 109 grains $/ \mathrm{m}^{3}$ in the end of August, they had the longest pollen season among all other taxa recorded, extending to 134 and 135 days, respectively.

In total, pollen taxa were detected in the atmosphere of NE Greece for 229 days, which corresponds to approximately $63 \%$ of the calendar year. Pollen circulation is generally low in autumn and the beginning of winter. Hence, allergic reactions recorded in sensitized individuals during this period must be due to other factors, including fungi, dust and mites. On the contrary, April and May were the months that pose the highest risk for pollen-induced allergies, with averaging total values of over 400 grains $/ \mathrm{m}^{3}$ in the atmosphere.

Compared to previous studies conducted in Greece, a significantly higher number of pollen were detected in the presented study $[16,17,18]$. However, the previous studies were conducted at least 10 years ago, and recent evidence show a tendency for an increase in pollen counts across Europe $[19,20]$. This increase may be due to changes in climatic factors or other anthropogenic forces, such as urban or industrial pollution. Pollen maturation, rapture grain and atmospheric dispersal are generally thought to be affected by these variables; however, this may not always be the case $[21,22]$.

In the present study, an association of pollen counts with meteorological parameters was attempted. With the exception of rainfall, all other climatic factors, namely average daily temperature, relative humidity and wind speed, were significantly associated with total pollen counts. Cupressaceae were associated with relative humidity and Oleacea with wind speed. Poaceae and Compositeae were associated with both average temperature and relative humidity, and the latter was also associated with wind speed. Interestingly, no association with climatic factors was found for Fagaceae and Pinaeae.

Several experiments have been conducted that used modeling approaches, with varying degrees of success, the discussion of which is beyond the scope of this study [23, 24]. Nonetheless, the information provided here can serve as a reference for both on-going and future research. The correlation of environmental and clinical data can generate epidemiological allergy records that are unique for this region. Evidence on seasonal aeroallergen levels can help generate an alarm system for sensitized individuals and clinicians. Protection from exposure and prophylactic medication can reduce referral to medical centres by as much as $50 \%$, thus reducing the cost of treatment $[25,26]$. 


\section{CONCLUSIONS}

Respiratory allergies are undoubtedly a major health burden that affects the quality of life of millions of people worldwide. However, due to the geographic zone, climate and ecological heterogeneities, a universal chart cannot apply, and regional monitoring systems are the only common denominator. Initiatives like this actually pay-off at the social, medical and economic scale; hence, an input from scientific and academic institutions specializing in aerobiology and population health is extremely valuable.

The presented study described the major pollen types circulating in the atmosphere of NE Greece, an area characterized by typical Mediterranean climate. Seasonal trends have been monitored and correlated with prevalent meteorological parameters. Future epidemiological studies will establish connections between respiratory allergies and pollen counts, which will allow the elucidation of environmental and clinical patterns coinciding with morbidity. This overlap of information is mandatory in order to better prepare medical interventions and to improve health indicators in the community.

\section{Acknowledgments}

This study was funded by the Ministry of Education of Greece (General Secretariat for Youth/No: 4636/18-12-2012), but they had no role in the study design, data collection and analysis, preparation of the manuscript or decision to publish.

\section{REFERENCES}

1. Gioulekas D, Papakosta D, Damialis A, Spieksma F, Giouleka P, Patakas D. Allergenic pollen records (15 years) and sensitization in patients with respiratory allergy in Thessaloniki, Greece. Allergy. 2004; 59: 174-184.

2. Makris M, Koulouris S, Koti I, Aggelides X, Sideri K, Chliva C, Vassilatou E, Kalogeromitros D. Temporal relationship of allergic rhinitis with asthma and other co-morbidities in a Mediterranean country: a retrospective study in a tertiary reference allergy clinic. Allergol Immunopathol. 2010; 38: 246-253.

3. Smith M, Jager S, Berger U, Sikoparija B, Hallsdottir M, Sauliene I, Bergmann KC, Pashley CH, de Weger L, Majkowska-Wojciechowska $\mathrm{B}$, et al. Geographic and temporal variations in pollen exposure across Europe. Allergy. 2014; 69: 913-923.

4. Ribeiro H, Oliveira M, Ribeiro N, Cruz A, Ferreira A, Machado H, Reis A, Abreu I. Pollen allergenic potential nature of some trees species: a multidisciplinary approach using aerobiological, immunochemical and hospital admissions data. Environ Res. 2009; 109: 328-333.

5. Myszkowska D, Jenner B, Stepalska D, Czarnobilska E. The pollen season dynamics and the relationship among some season parameters (start, end, annual total, season phases) in Krakow, Poland, 1991-2008. Aerobiologia. 2011; 27: 229-238.

6. Alexandropoulos T, Haidich AB, Pilalas D, Dardavessis T, Daniilidis M, Arvanitidou M. Characteristics of patients with allergic rhinitis in an outpatient clinic: a retrospective study. Allergol Immunopathol. 2013; 41: 194-200.

7. Arshad SH, Karmaus W, Matthews S, Mealy B, Dean T, Frischer T, Tsitoura S, Bojarskas J, Kuehr J, Forster J. Association of allergy-related symptoms with sensitisation to common allergens in an adult European population. J Investig Allergol Clin Immunol. 2001; 11: 94-102.

8. Baran H, Ozcan KM, Selcuk A, Cetin MA, Cayir S, Ozcan M, Dere H. Allergic Rhinitis and its Impact on Asthma classification correlations. J Laryngol Otol. 2014; 128: 431-437.

9. Yalcin AD, Basaran S, Bisgin A, Polat HH, Gorczynski RM. Pollen aero allergens and the climate in Mediterranean region and allergen sensitivity in allergic rhinoconjunctivitis and allergic asthma patients. Med Sci Monit. 2013; 19: 102-110.

10. Grant Smith E. Sampling and identifying allergenic pollens and molds. An Illustrated Manual for Physicians and Lab Technicians. Blewstone Press, San Antonio, Texas, 1984.

11. British Aerobiological Federation. Airborne pollens and spores: A guide to trapping and counting. Rotherham, UK, 1995.

12. Kasprzyk I. Forecasting the start of Quercus pollen season using several methods - the evaluation of their efficiency. Int J Biometeorol. 2009; 53: 345-353.

13. Rodriguez R, Villalba M, Batanero E, Palomares O, Salamanca G. Emerging pollen allergens. Biomed Pharmacother. 2007; 61: 1-7.

14. Rodriguez de la Cruz D, Sanchez Reyes E, Sanchez Sanchez J. Effects of meteorological factors on airborne bracken (Pteridium aquilinum (L.) Kuhn.) spores in Salamanca (middle-west Spain). Int J Biometeorol. 2009; 53: 231-237.

15. Bosch-Cano F, Bernard N, Sudre B, Gillet F, Thibaudon M, Richard H, Badot PM, Ruffaldi P: Human exposure to allergenic pollens: a comparison between urban and rural areas. Environ Res. 2011; 111: 619-625.

16. Gioulekas D, Balafoutis C, Damialis A, Papakosta D, Gioulekas G, Patakas D. Fifteen years' record of airborne allergenic pollen and meteorological parameters in Thessaloniki, Greece. Int J Biometeorol. 2004; 48: 128-136.

17. Gioulekas D, Damialis A, Papakosta D, Syrigou A, Mpaka G, Saxoni F, Patakas D. 15-year aeroallergen records. Their usefulness in Athens Olympics, 2004. Allergy. 2003; 58: 933-938.

18. Gonianakis M, Neonakis I, Gonianakis I, Baritaki M, Kypriotakis Z, Potamias G, Bouros D, Kontou-Fili K. A 10-year aerobiological study (1994-2003) in the Mediterranean island of Crete, Greece: grasses and other weeds, aerobiological data, and botanical and clinical correlations. Allergy Asthma Proc. 2006; 27: 363-370.

19. D’Amato G, Cecchi L, Bonini S, Nunes C, Annesi-Maesano I, Behrendt H, Liccardi G, Popov T, van Cauwenberge P. Allergenic pollen and pollen allergy in Europe. Allergy. 2007; 62: 976-990.

20. Ziello C, Sparks TH, Estrella N, Belmonte J, Bergmann KC, Bucher E, Brighetti MA, Damialis A, Detandt M, Galan C, et al. Changes to airborne pollen counts across Europe. PLoS One. 2012; 7: e34076.

21. Cassagne E, Caillaud D, Besancenot JP, Thibaudon M. Forecasting the onset of an allergic risk to poaceae in Nancy and Strasbourg (France) with different methods. Eur Ann Allergy Clin Immunol. 2008; 40:14-21.

22. Damialis A, Gioulekas D, Lazopoulou C, Balafoutis C, Vokou D. Transport of airborne pollen into the city of Thessaloniki: the effects of wind direction, speed and persistence. Int J Biometeorol. 2005; 49:139-145.

23. Rodriguez-Rajo FJ, Astray G, Ferreiro-Lage JA, Aira MJ, Jato-Rodriguez MV, Mejuto JC. Evaluation of atmospheric Poaceae pollen concentration using a neural network applied to a coastal Atlantic climate region. Neural Netw. 2010; 23: 419-425.

24. Smith M, Emberlin J. A 30-day-ahead forecast model for grass pollen in north London, United Kingdom. Int J Biometeorol. 2006; 50: 233-242.

25. Douladiris N, Savvatianos S, Roumpedaki I, Skevaki C, Mitsias D, Papadopoulos NG. A molecular diagnostic algorithm to guide pollen immunotherapy in southern Europe: towards component-resolved management of allergic diseases. Int Arch Allergy Immunol. 2013; 162: $163-172$.

26. Anastassakis K, Chatzimichail A, Androulakis I, Charisoulis S, Riga M, Eleftheriadou A, Danielides V. Skin prick test reactivity to common aeroallergens and ARIA classification of allergic rhinitis in patients of Central Greece. Eur Arch Otorhinolaryngol. 2010; 267: 77-85. 